\title{
Effect of progressive muscle relaxation technique on stress, anxiety, and depression after hysterectomy
}

\author{
Rasha Mohamed Essa *1, Nemat Ismail Abdel Aziz Ismail ${ }^{1}$, Nagia Ibrahim Hassan ${ }^{2}$ \\ ${ }^{1}$ Obstetric and Gynecologic Nursing, Faculty of Nursing, Damnhour University, Damnhour, Egypt \\ ${ }^{2}$ Psychiatric Nursing and Mental Health, Faculty of Nursing, Damnhour University, Damnhour, Egypt
}

Received: July 31, 2016

Accepted: December 6, 2016

Online Published: February 20, 2017

DOI: $10.5430 /$ jnep.v7n $7 \mathrm{p} 77$

URL: https://doi.org/10.5430/jnep.v7n7p77

\begin{abstract}
Progressive muscle relaxation (PMR) is one the systematic techniques that could be utilized to obtain a deep state of relaxation. It is an important component of nursing care for gynecological postoperative patients. The aim of this study was to determine the effect of progressive muscle relaxation technique on stress, anxiety and depression after hysterectomy. A quasi experimental research design with a pretest-posttest control group was utilized. The study was conducted at the gynecological ward of National Medical Institution in Damanhour, Albehera Governorate. Collection of data consumed six months from starting of December 2014 until the end of May 2015. It comprised a purposive sample of 80 women who were undergoing abdominal hysterectomy. They were divided into two equal groups (study group and control group). Two tools were utilized to gather the necessary data; a socio-demographic structured interview schedule, and the Depression, anxiety and stress scale (DASS-21). Study results revealed that stress, anxiety and depression were statistically significantly decreased among the study group after the intervention $(p=.000)$. The study concluded that the women who received progressive muscle relaxation technique after hysterectomy demonstrated lower stress, anxiety and depression levels than those who received only the routine nursing care. It is recommended that maternity and gynecological nursing should encourage the utilization of the progressive muscle relaxation technique to patients undergoing hysterectomy to minimize their stress, anxiety and depression.
\end{abstract}

Key Words: Progressive muscle relaxation technique, Hysterectomy, Stress, Anxiety, Depression

\section{INTRODUCTION}

Worldwide, women's reproductive health is an issue of vital importance and one that has wide spread implications on health, well being and development of the entire population. Hysterectomy is one of the most common gynecological operations done throughout the world. ${ }^{[1]}$ The term of Hysterectomy comes from the two Greek words, first one is "hystera" which means uterus, and the second one is "ectomy" which means removal, so hysterectomy is the surgical operation of removing the uterus which usually includes the cervix (neck of the uterus). It was considered as the second common surgical operation among women of reproductive age after cesarean section. ${ }^{[2,3]}$ The most common reasons for hysterectomy are conditions like excessive bleeding, uterine leiomyomas, endometriosis, adenomyosis, uterine prolapse, Pelvic Inflammatory Disease, and cancer of the reproductive tract. ${ }^{[4]}$

Hysterectomy clients are bound to feel more stress because no other surgical procedure has such significant meaning to women involving alteration in their reproductive organ. Gynecological clients often require more understanding than other clients, because of the emotional as well as physical

\footnotetext{
*Correspondence: Rasha Mohamed Essa; Email: rashaessa111@yahoo.com; Address: Obstetric and Gynecologic Nursing, Faculty of Nursing, Damnhour University, Damnhour, Egypt.
} 
consideration of the particular situation. ${ }^{[5]}$ The uterus is a symbol of femininity, fertility, motherhood, and sexuality for most of the women. And with hysterectomy some women may feel that they are less femininity because of the loss of monthly period, or they may fear that they will lose sensual and sexual capacity and they will be rejected by their partners. The biggest fear represented in the permanent loss of the childbearing role. Some women feel that they are not properly female unless they are able to have children, even women with already large families can feel this kind of loss. ${ }^{[6,7]}$

Hysterectomy operation is considered as the most stressful situation by many women. It carries the stress of a surgery and a possibility of postoperative complications and has been associated with anxiety, depression, changes in self-esteem, and in sexual functioning. Earlier studies have reported that the majority of posthysterectomy women can be permanently depressed and can also exhibit symptoms of mixed anxiety and depressive disorder. ${ }^{[8,9]}$

Khastiger et al. (2000) reported that the majority of retrospective studies have shown a negative psychological consequence after hysterectomy. However, all prospective studies had revealed that the incidence of depressed mood is higher even before hysterectomy, owing to psychiatric illness and personality and psychosocial problems that already exist. ${ }^{[10]}$ In addition study done by DeCherney et al. (2002) showed that depression can be evident in the form of tiredness and this could be experienced by $74 \%$ of women after hysterectomy. ${ }^{[11]}$ Moreover, Cooper et al. (2009) had stated that women referred to psychiatrists much more commonly following removal of the uterus than any other operation and the most psychogical reactions are depression and anxiety. They added that anxiety and depression are common preoperatively among women undergoing hysterectomy compared to the rest of the population. ${ }^{[12]}$ Another study done by Sehlo \& Ramadani (2010) mentioned that women after hysterectomy may display anxiety and depression in the form of body complaints and reduced social well being even 24 weeks postoperatively. ${ }^{[13]}$

It is a real fact that there are physical and emotional sequels, that includ pain, changes in body image and sexual life depression, deteriorate social life, anxiety, and guilt to the removal of the uterus which can threaten women's self worth. The alleviation of psychological problems as stress, anxiety and depression is one of the maternity and gynecological nurse's challenges. Where, the nurse ought to help the women to cope successfully. Generally speaking stress management could be pharmacological and/or nonpharmacological. Where pharmacological techniques are expensive and usually associated with complications. Recent studies focused on non-pharmacological methods. ${ }^{[14,15]}$

Progressive muscle relaxation technique (PMRT) is one of the non pharmacological interventions to overcome these problems. It decreases stress through its effect on mental and physical conditions, mood, depression, and anxiety. Relaxation methods are very powerful tools for dealing with stress, depression and anxiety by giving the body/mind the chance to make its own healing. Relaxation method retrieves harmony and helps to create these conditions for optimum living. It is the relieving of mental and physical stress. Some people need help and training to understand how to relieve the mental and physical stress. ${ }^{[16-18]}$

Among the relaxation methods, progressive muscle relaxation technique, is the easiest one to be learnt and administered. This intervention is inexpensive, available, self induced by the patient and free from side effects. It is a systematic technique to reduce stress and attain a deep state of relaxation. It increases body's immunity and sense of well-being through endorphins release. Ultimately, an improvement in adaptive functioning may be realized. Client with anxiety, depression, stress, tension headaches, insomnia, muscle spasms; lower back pain, fatigue, irritable bowel and hypertension are among those, who can achieve positive results using this technique. ${ }^{[19,20]}$

As early as 1930, Dr. Edmund Jacobson had developed the PMRT. He discovered that a muscle could be relaxed by first tensing it for a few seconds and then releasing it. Where clients are asked to intentionally contract muscle and hold the tension; after that they release all tension and focus on the sensation of relaxation. Progressive muscle relaxation helps people identify which muscles or muscle groups are chronically tense by distinguishing between sensations of tension (purposeful muscle tensing) and relaxation (a conscious relaxing of the muscles). Each muscle or muscle grouping is tensed for 5-7 seconds and after that they relaxed for 20-30 seconds. During each time, the individual focuses on the difference in sensations between the two conditions. The awareness of the relaxing sensation is one of the greatest gains realized with progressive muscle relaxation. ${ }^{[21,22]}$

In spite of the importance of reducing stress, anxiety and depression among pre and post hysterectomy women, there is lack of evidence to evaluate the effect of PMRT in stress, anxiety and depression among post hysterectomy women in Egypt. Therefore, the study aims to evaluate the effect of PMRT on reducing stress, anxiety and depression in posthysterectomy women. 


\subsection{Aim of the study}

The aim of this study is to determine the effect of progressive muscle relaxation technique on stress, anxiety and depression after hysterectomy.

\subsection{Hypothesis}

- Women who receive progressive muscle relaxation technique after hysterectomy opration exhibit less stress than those who do not receive it.

- Women who receive progressive muscle relaxation technique after hysterectomy opration exhibit less anxiety than those who do not receive it.

- Women who receive progressive muscle relaxation technique after hysterectomy opration exhibit less depression than those who do not receive it.

\subsection{Operational definition}

Progressive Muscle Relaxation (PMR): In this study refers to a technique that involves the systematic tensing and relaxing of specific muscle groups as face, hand, leg, shoulder and abdomen.

\section{Materials AND METHOD}

\subsection{Research design}

A quasi experimental research design with a pretest-posttest control group was utilized.

\subsection{Setting}

This study was conducted in maternity ward of National Medical Institution in Damanhour, Albehera Governorate. This hospital is the largest referral hospital for gynecology and obstetrics cases in Albehera Governorate and receives women of different socioeconomic status from all Governorate.

\subsection{Subjects}

The study subjects were selected through a non-probability sampling technique. A purposive sample of 80 women undergoing abdominal hysterectomy was recruited. The sample size was estimated based on the Epi-Info 7 program using the following parameters:

(1) Target population 430 per 3 months;

(2) Expected frequency $p=50 \%$;

(3) Acceptable error $=10 \%$;

(4) Confidence coefficient $=95 \%$;

(5) Sample size $=80$.

The study subjects enrolled in this study according to the following inclusion criteria: women who undergoing abdominal hysterectomy and accept to participate in the study. The researchers excluded women who had a major operation within the last 3 years, those with chronic health problems such as Diabetes or Cardiovascular disease, those with a history of psychiatric disorders and those having the operation for a malignant condition. Total sample size (80) was allocated to either a study (40) or control (40) group.

\subsection{Tools}

Two tools were used for data collection.

\section{Tool 1: Socio-demographic structured interview schedule} It was specifically designed by the researchers and used to gather data about subjects' socio- demographic data such as: age, occupation, marital status, current residence, level of education, number of children, and indication of operation.

Tool 2: The depression anxiety and stress scale (DASS-21) It was developed by Lovibond and Lovibond (1995). ${ }^{[23]}$ DASS 21 was adopted and translated to an Arabic version to be used in the current study. It is a 21 items self-report inventory that yields negative aspect of emotions, namely depression, anxiety and stress. Each of the three parts of the DASS scale contains 7 items. Women were asked to use 4-point severity/frequency scale to rate the extent to which they had experienced each state over the past week. This scale is as follows: Did not apply to me at all $=0$, Applied to me to some degree, or some of the time $=1$, Applied to me to a considerable degree, or a good part of time $=2$, and Applied to me very much, or most of the time $=3$. Scores for depression, anxiety and stress were calculated by summing the scores for the relevant items. The total score of depression was classified as follows: Score 0-4 is considered normal, 5-6 mild, 7-10 moderate, 11-13 severe, and higher than 14 is very severe. While the total score of anxiety was: 0-3 is normal, 4-5 mild, 6-7 moderate, 8-9 severe, and higher than 10 is very severe. In addition, the total score of stress was: Scores from 0-7 is normal, 8-9 mild, 10-12 moderate, $13-16$ severe, and higher than 17 is very severe. ${ }^{[24]}$

\subsection{Procedures}

(1) Permissions for data collection were obtained from the responsible authorities after explanation of the purpose of the study.

(2) After reviewing the recent literature tool 1 was developed by the researchers, then it was validated by jury of five experts in the obstetric and gynecologic nursing as well as psychiatric nursing. Tool 2 was adopted, and translated into Arabic language then it was reviewed by the same juries to ensure the content validity of the translated version with the original one. Test-re-test reliability was carried out for tool 2 within two weeks interval on 8 women, where cronbach's alpha test was satisfactory (0.82). 
(3) Each woman in both group was individually contracted and informed about the aim of the study in order to obtain her oral informed consent. The confidentiality and anonymity of individual responses, volunteer participation and right to refuse participating in the study were emphasized to the women.

(4) A pilot study was conducted on 8 women who are undergoing abdominal hysterectomy (excluded from the study subjects) to test the feasibility of the tools as well as to ascertain their clarity and applicability. In addition, the time needed to complete the tools was also estimated. After pilot study the tools were revised, reconstructed and made ready for use.

(5) The first 40 women who fulfill the criteria for inclusion in the study were recruited as the control group. The subjects in the control group were left for hospital routine care and the researchers take them first to avoid contamination of data. In the day before the operation the researchers interviewed each woman individually for about 20 minutes; the researchers introduced themselves to the woman, and explained the purpose of the study as well as oral consent was obtained then tool 1 and tool 2 (pre-test) were collected from the woman. In the fourth day post-operative the tool 2 was re-administered for the control group as post-test.

(6) Then the following 40 women who fulfill the same criteria for inclusion in the study were recruited as the study group. Where the researchers interviewed each woman individually on the day before the operation for about 60 minutes; the researchers introduced themselves to the woman, and explained the purpose of the study and benefit, steps, frequency and duration of progressive muscle relaxation technique. During this interview oral consent was obtained then tool 1 was collected from the woman, after that tool 2 was applied as pre-test.

(7) Training of each woman in the study group on progressive muscle relaxation technique started after the depression anxiety and stress pre-test was completed, the researchers gave information to the woman individually about progressive muscle relaxation technique. It was explained that each muscle group will be tensed for 10 seconds and then relaxed for 10 seconds, and that the muscles in the body are divided into twelve groups, the first one is the muscles of the hands, the second is the biceps and triceps muscles, the third is the muscles of the shoulders, the fourth is the muscles of the neck, the fifth is the muscles of the mouth and jaw, the sixth is the muscles of the eyes and forehead, the seventh is the chest muscles, the eighth is the abdominal muscles, the ninth is the back muscles, the tenth is the muscles of the thighs, the eleventh is the muscles of the legs, and finally the last group is the muscles of the feet.

(8) After giving information to the woman, she was asked to sit down on the chair in a comfortable position and to close her eyes and keep them closed (if possible) till the end of the technique. As for the relaxation training, the researchers demonstrated each step of PMR technique then asked the woman to re-demonstrate it. The researchers then asked the woman to re-demonstrate all the steps and repeat the technique for three to four times until the woman masters it.

(9) In the second, third and fourth days post-operative, the woman was asked to demonstrate the technique for 30 minutes, three times per day in morning, evening and night shifts with the help and supervision of the researchers.

(10) After nine sessions (in fourth day) of PMR technique the depression, anxiety and stress were assessed by using tool 2 (post test).

(11) Collection of data consumed six months from starting of December 2014 until the end of May 2015.

(12) Data analysis was carried out by the researchers using (SPSS program version 16). The collected data was categorized, coded, computerized, tabulated and analyzed using percentage, mean, standard deviations and comparison between study and control group was done by fisher exact test, $T$-test, and Chi-square-test. The $p$ $\leq .01$ was used to indicate statistical significance.

\section{RESULTS}

Table 1 shows no significant difference between the two groups in their socio-demographic data. Where, the majority among both the study (80\%) and control (77.5\%) groups were 45 or more years old. Around one-half (50\% \& 47.5\%) of the study and the control group respectively, had primary or preparatory level of education. Three quarters (75\%) of the study $\& 70 \%$ of the control groups were housewives. The majority $(77.5 \%$ and $80 \%)$ of the study and control groups respectively, were rural residents. Nearly the same percent of the study and control groups $(72.5 \%$ and $75 \%$ respectively) were married. The majority of the study and the control groups $(87.5 \%$ \& $80 \%$ respectively) had one child or more. As for the indication of operation (60\% and 62.5\%) of both groups respectively had reported that abnormal uterine bleeding is the main indication for hysterectomy. 
Table 1. Socio-demographic data among the study group (progressive relaxation) and control group

\begin{tabular}{|c|c|c|c|c|c|}
\hline \multirow{2}{*}{ Socio-demographic } & \multicolumn{2}{|c|}{ Study Group $(n=40)$} & \multicolumn{2}{|c|}{ Control Group $(n=40)$} & \multirow{2}{*}{$\chi^{2}(P)$} \\
\hline & $\mathbf{N}$ & $\%$ & $\mathbf{N}$ & $\%$ & \\
\hline \multicolumn{5}{|l|}{ Age (years) } & \multirow{3}{*}{$\begin{array}{l}0.075 \\
(.784)\end{array}$} \\
\hline$<45$ years & 8 & 20.0 & 9 & 22.5 & \\
\hline$\geq 45$ years & 32 & 80.0 & 31 & 77.5 & \\
\hline \multicolumn{5}{|l|}{ Level of education } & \multirow{4}{*}{$\begin{array}{l}0.246 \\
(.884)\end{array}$} \\
\hline Secondary or more & 8 & 20.0 & 7 & 17.5 & \\
\hline Primary/preparatory & 20 & 50.0 & 19 & 47.5 & \\
\hline Illiterate/read \& write & 12 & 30.0 & 14 & 35.0 & \\
\hline \multicolumn{5}{|l|}{ Occupation } & \multirow{3}{*}{$\begin{array}{l}0.251 \\
(.616)\end{array}$} \\
\hline Housewife & 30 & 75.0 & 28 & 70.0 & \\
\hline Working & 10 & 25.0 & 12 & 30.0 & \\
\hline \multicolumn{5}{|l|}{ Current residence } & \multirow{3}{*}{$\begin{array}{l}0.075 \\
(.784)\end{array}$} \\
\hline Rural & 31 & 77.5 & 32 & 80.0 & \\
\hline Urban & 9 & 22.5 & 8 & 20.0 & \\
\hline \multicolumn{5}{|l|}{ Marital status } & \multirow{3}{*}{$\begin{array}{l}0.065 \\
(.799)\end{array}$} \\
\hline Not marred & 11 & 27.5 & 10 & 25.0 & \\
\hline Marred & 29 & 72.5 & 30 & 75.0 & \\
\hline \multicolumn{3}{|l|}{ Number of children } & & & \multirow{3}{*}{$\begin{array}{l}0.827 \\
(.363)\end{array}$} \\
\hline None & 5 & 12.5 & 8 & 10.0 & \\
\hline One or more & 35 & 87.5 & 32 & 80.0 & \\
\hline \multicolumn{6}{|l|}{ Indication of operation } \\
\hline Abnormal Uterine Bleeding & 24 & 60.0 & 25 & 62.5 & \multirow{3}{*}{$\begin{array}{l}0.337 \\
(.845)\end{array}$} \\
\hline Endometrial Hyperplasia & 7 & 17.5 & 8 & 20.0 & \\
\hline Fibroid uterus & 9 & 22.5 & 7 & 17.5 & \\
\hline
\end{tabular}

* Significant at $p \leq .01$

Table 2 exhibits total score of stress among the study and the control groups before and after the intervention. As much as $42.5 \%$ of the study \& $40 \%$ of the control groups had very severe stress before the intervention. Yet, the difference between the two groups in this respect was statistically not significant $(p=.760)$. After the intervention, the difference between the two groups were found to be statistically signifi- cant $(p=.000)$. Where, one quarter $(25 \%)$ of the study group had no stress (normal) in comparison with just $2.5 \%$ among the control group. In addition, the very severe stress had completely disappeared among the study group compared to around one-third (32.5\%) of the control group. Meanwhile, $30 \%, 25 \%$ and $10 \%$ of the control group were still suffering from severe, moderate, and mild, respectively.

Table 2. Total score of stress among the study and the control groups before and after the intervention

\begin{tabular}{|c|c|c|c|c|c|c|c|c|c|c|}
\hline \multirow{3}{*}{$\begin{array}{l}\text { Total score of } \\
\text { stress }\end{array}$} & \multicolumn{4}{|c|}{ Study group = 40} & \multicolumn{4}{|c|}{ Control group $=40$} & \multirow{3}{*}{$\begin{array}{l}\text { FET/(P) } \\
\text { Before }\end{array}$} & \multirow{3}{*}{$\begin{array}{l}\text { FET/(P) } \\
\text { After }\end{array}$} \\
\hline & \multicolumn{2}{|c|}{$\begin{array}{l}\text { Before } \\
\text { intervention }\end{array}$} & \multicolumn{2}{|c|}{$\begin{array}{l}\text { After } \\
\text { intervention }\end{array}$} & \multicolumn{2}{|c|}{$\begin{array}{l}\text { Before } \\
\text { intervention }\end{array}$} & \multicolumn{2}{|c|}{$\begin{array}{l}\text { After } \\
\text { intervention }\end{array}$} & & \\
\hline & No. & $\%$ & No. & $\%$ & No. & $\%$ & No. & $\%$ & & \\
\hline Normal (0-7) & 0 & 00.0 & 10 & 25.0 & 0 & 00.0 & 1 & 02.5 & & \\
\hline Mild (8-9) & 3 & 7.5 & 15 & 37.5 & 5 & 12.5 & 4 & 10.0 & & \\
\hline Moderate (10-12) & 7 & 17.5 & 12 & 30.0 & 9 & 22.5 & 10 & 25.0 & 1.172 & 32.314 \\
\hline Severe (13-16) & 13 & 32.5 & 3 & 7.5 & 10 & 25.0 & 12 & 30.0 & $(0.760)$ & $(0.000) *$ \\
\hline Very severe $(>17)$ & 17 & 42.5 & 0 & 00.0 & 16 & 40.0 & 13 & 32.5 & & \\
\hline $\mathrm{FET} / 2(P)$ & \multicolumn{4}{|c|}{$42.566(.000) *$} & \multicolumn{4}{|c|}{$1.656(.799)$} & & \\
\hline
\end{tabular}

*: Significant at $p \leq .01$

Table 3 demonstrates the stress mean scores of the study and control groups before and after the intervention. At the pre-intervention, although the stress mean score among the study group was higher than that of the control group $(15.200 \pm 3.838$ and $14.625 \pm 3.894$ respectively), there was no statistical significant difference, where $t$-test $=0.665$ 
and $p=.508$. After intervention, the study group has attained nearly $50 \%$ decrease in the stress mean score $(8.200$ $\pm 3.568)$ as compared to $(15.200 \pm 3.838)$ obtained in the pre-intervention. Comparing the stress mean score obtained with the control group $(14.575 \pm 3.889)$. The relationship between two groups was statistically significant, where $p=$
.000. The difference between the means stress score among the study group before and after the intervention was statistically significant $(p=.000)$. Whereas the same difference among the control group was not statistically significant ( $p=$ $.954)$.

Table 3. Stress mean scores of the study and control groups before and after the intervention

\begin{tabular}{llll}
\hline \multirow{2}{*}{ Mean total score of stress } & Study Group $(\mathbf{n}=\mathbf{4 0})$ & Control Group $(\mathbf{n}=\mathbf{4 0})$ & \multirow{2}{*}{$\boldsymbol{T}$ test $(\boldsymbol{p})$} \\
\cline { 2 - 4 } & Mean \pm SD & Mean \pm SD & $0.665(.508)$ \\
\hline Before intervention & $15.200 \pm 3.838$ & $14.625 \pm 3.894$ & $7.639(.000) *$ \\
After intervention & $8.200 \pm 3.568$ & $14.575 \pm 3.889$ & $0.057(.954)$ \\
$T$ test $(p)$ & $8.448(.000) *$ & & \\
\hline
\end{tabular}

* Significant at $p \leq .01$

Table 4 represents total score of anxiety among the study and the control groups before and after the intervention. Before the intervention, almost equal proportions (37\% and $35 \%$ ) of the study and control groups respectively, had very severe total score of anxiety. Meanwhile, around one-fifth $(17.5 \%)$ of the study group had moderate total score of anxiety compared to only $25 \%$ of the control group. There is no statistically significant difference between them where $p=.675$. After intervention, such difference between both groups were found to be statistically significant $(p<.0000)$. Where, $35 \%$ of the control group still had severe anxiety in comparison with $5 \%$ of the study group. In addition, anxiety had completely disappeared among one-fifth $(20 \%)$ of the study group, compared to no one $(0.00 \%)$ of the control group. At the same time there was a statistically significant decrease within the study group $(p=.000)$.

Table 4. Total score of anxiety among the study and the control groups before and after the intervention

\begin{tabular}{|c|c|c|c|c|c|c|c|c|c|c|}
\hline \multirow{3}{*}{$\begin{array}{l}\text { Total score of } \\
\text { anxiety }\end{array}$} & \multicolumn{4}{|c|}{ Study group $=40$} & \multicolumn{4}{|c|}{ Control group $=40$} & \multirow{3}{*}{$\begin{array}{l}\text { FET/2(P) } \\
\text { Before }\end{array}$} & \multirow{3}{*}{$\begin{array}{l}\text { FET/2(P) } \\
\text { After }\end{array}$} \\
\hline & \multicolumn{2}{|c|}{$\begin{array}{l}\text { Before } \\
\text { intervention }\end{array}$} & \multicolumn{2}{|c|}{$\begin{array}{l}\text { After } \\
\text { intervention }\end{array}$} & \multicolumn{2}{|c|}{$\begin{array}{l}\text { Before } \\
\text { intervention }\end{array}$} & \multicolumn{2}{|c|}{$\begin{array}{l}\text { After } \\
\text { intervention }\end{array}$} & & \\
\hline & No. & $\%$ & No. & $\%$ & No. & $\%$ & No. & $\%$ & & \\
\hline Normal (0-3) & 0 & 00.0 & 8 & 20.0 & 1 & 02.5 & 0 & 00.0 & \multirow{5}{*}{$\begin{array}{l}2.335 \\
(.675)\end{array}$} & \multirow{5}{*}{$\begin{array}{l}39.338 \\
(.000) *\end{array}$} \\
\hline Mild (4-5) & 2 & 05.0 & 18 & 45.0 & 3 & 07.5 & 4 & 10.0 & & \\
\hline Moderate (6-7) & 7 & 17.5 & 12 & 30.0 & 10 & 25.0 & 9 & 22.5 & & \\
\hline Severe (8-9) & 16 & 40.0 & 2 & 05.0 & 12 & 30.0 & 14 & 35.0 & & \\
\hline very severe $(>10)$ & 15 & 37.5 & 0 & 00.0 & 14 & 35.0 & 13 & 32.5 & & \\
\hline $\mathrm{FET} / 2(P)$ & \multicolumn{4}{|c|}{$48.005(.000) *$} & \multicolumn{4}{|c|}{$1.386(.847)$} & & \\
\hline
\end{tabular}

* Significant at $p \leq .01$

Table 5 presents the anxiety mean scores among the study and the control groups before and after the intervention. Considering the pre-intervention, the study group was obtained $(9.525 \pm 3.146)$ mean score of anxiety and $10.075 \pm 4.790$ was obtained in the control group. The two mean scores were close to each other with no statistically significant difference $p=.544$. After intervention, a great declined in the anxiety mean scores was obtained by the study group (4.575 \pm 2.011 ) while it was $10.175 \pm 4.679$ for the control group Here the difference between both groups was statistically significant $(p=.000)$. In addition, The difference between the means anxiety score among the study group before and after the intervention was statistically significant $(p=.000)$. Whereas the same difference among the control group was not statistically $\operatorname{significant}(p=.925)$.

According to Table 6, more than two-thirds of the study (72.5\%) and the control (72\%) groups had moderate depression pre intervention, the relationship between both groups was not statistically significant. Following the intervention, a statistically significant difference was found among the study group and the control group ( $p=.000)$. One-half $(50 \%)$ of the study group had mild depression compared to $25 \%$ of the study group. The same symptoms were completely absent 
in $37.5 \%$ of the study group compared only $7.5 \%$ among the control group. At the same time the change within the study group was significant $(p<.000)$ after intervention, while, the difference among the control group was statistically not significant.

Table 7 shows depression mean scores of the study and control groups before and after the intervention. At the preintervention, the depression mean score didn't differ significantly among the study and the control groups $(8.175$ \pm 1.738 and $7.825 \pm 1.567$ respectively), where $p=.347$. Immediately after intervention, the depression mean score decreased in the study group while it is nearly the same in the control groups. The study group has achieved about fifty percent decrease in its depression mean score (4.200 \pm 2.334). While the depression mean score was $7.625 \pm 1.890$ for the control group. Consequently, the difference between the two groups were found to be statistically ( $p \leq .0001)$. Table 7 also indicates that the difference between the means depression score within the study group before and after the intervention was statistically significant $(p=.000)$. However, a significant difference was not observed among the control group $(p=.607)$.

Table 5. Anxiety mean scores of the study and control groups before and after the intervention

\begin{tabular}{llll}
\hline \multirow{2}{*}{ Mean total score of anxiety } & Study Group $(\mathbf{n}=\mathbf{4 0})$ & Control Group $(\mathbf{n}=\mathbf{4 0})$ & \multirow{2}{*}{ T test $(\boldsymbol{p})$} \\
\cline { 2 - 4 } & $\mathbf{M e a n} \pm \mathbf{S D}$ & Mean \pm SD & $0.607(.544)$ \\
\hline Before intervention & $9.525 \pm 3.146$ & $10.075 \pm 4.790$ & $6.954(.000) *$ \\
After intervention & $4.575 \pm 2.011$ & $10.175 \pm 4.679$ & $0.094(.925)$ \\
\hline test $(p)$ & $8.385(.000) *$ & & \\
\hline
\end{tabular}

* Significant at $p \leq .01$

Table 6. Total score of depression among the study and the control groups before and after the intervention

\begin{tabular}{|c|c|c|c|c|c|c|c|c|c|c|}
\hline \multirow{3}{*}{$\begin{array}{l}\text { Total score of } \\
\text { depression }\end{array}$} & \multicolumn{4}{|c|}{ Study group $=40$} & \multicolumn{4}{|c|}{ Control group $=40$} & \multirow{3}{*}{$\begin{array}{l}\text { FET/(P) } \\
\text { Before }\end{array}$} & \multirow{3}{*}{$\begin{array}{l}\text { FET/(P) } \\
\text { After }\end{array}$} \\
\hline & \multicolumn{2}{|c|}{$\begin{array}{l}\text { Before } \\
\text { intervention }\end{array}$} & \multicolumn{2}{|c|}{$\begin{array}{l}\text { After } \\
\text { intervention }\end{array}$} & \multicolumn{2}{|c|}{$\begin{array}{l}\text { Before } \\
\text { intervention }\end{array}$} & \multicolumn{2}{|c|}{$\begin{array}{l}\text { After } \\
\text { intervention }\end{array}$} & & \\
\hline & No. & $\%$ & No. & $\%$ & No. & $\%$ & No. & $\%$ & & \\
\hline Normal (0-4) & 0 & 00.0 & 15 & 37.5 & 0 & 00.0 & 3 & 07.5 & \multirow{5}{*}{$\begin{array}{l}0.061 \\
(.999)\end{array}$} & \multirow{5}{*}{$\begin{array}{l}26.458 \\
(.000) *\end{array}$} \\
\hline Mild (5-6) & 11 & 27.5 & 20 & 50.0 & 12 & 30.0 & 10 & 25.0 & & \\
\hline Moderate $(7-10)$ & 29 & 72.5 & 5 & 12.5 & 28 & 70.0 & 27 & 67.5 & & \\
\hline Severe (11-13) & 0 & 00.0 & 0 & 00.0 & 0 & 00.0 & 0 & 00.0 & & \\
\hline Very severe $(>14)$ & 0 & 00.0 & 0 & 00.0 & 0 & 00.0 & 0 & 00.0 & & \\
\hline $\mathrm{FET} / 2(P)$ & \multicolumn{4}{|c|}{$34.554(.000) *$} & \multicolumn{4}{|c|}{$3.2(.525)$} & & \\
\hline
\end{tabular}

* Significant at $p \leq .01$

Table 7. Depression mean scores of the study and control groups before and after the intervention

\begin{tabular}{llll}
\hline \multirow{2}{*}{ Mean total score of depression } & Study Group $(\mathbf{n}=\mathbf{4 0})$ & Control Group $(\mathbf{n}=\mathbf{4 0})$ & \multirow{2}{*}{$\boldsymbol{T}$ test $(\boldsymbol{p})$} \\
\cline { 2 - 4 } & $\mathbf{M e a n} \pm \mathbf{S D}$ & Mean \pm SD & $0.946(.347)$ \\
\hline Before intervention & $8.175 \pm 1.738$ & $7.825 \pm 1.567$ & $7.213(.000) *$ \\
After intervention & $4.200 \pm 2.334$ & $7.625 \pm 1.890$ & \\
$T$ test $(p)$ & $8.639(.000) *$ & $0.515(.607)$ & \\
\hline
\end{tabular}

* Significant at $p \leq .01$

\section{Discussion}

In the literature anxiety, depression and stress have been frequently associated with women after hysterectomy. They can compromise compliance with treatment and the negative affect overall quality of life, prognosis, and the rates of survival. These problems in post hysterectomy patients need more comprehensive management that extends beyond

Published by Sciedu Press the use of just pharmacological interventions. Various nonpharmacological measures have been tested as adjuvant treatments for reducing anxiety, depression and stress including massage, and PMRT. PMRT is one systematic technique which can be used to acquire a profound state of relaxation and might be an essential element on nursing care for gynecological postoperative women. ${ }^{[25,26]}$ 
The researches carried out to measure the effect of progressive muscle relaxation technique on the anxiety, stress and depression of women with hysterectomy are rare. However, many studies in different fields such as (stoma, cardiac rehabilitation, dialysis, psychiatric and chemotherapy patients) have confirmed that (PMRT) to be effective in the reduction of stress, anxiety and depression.

The present study revealed that stress mean score had significantly decreased after the application of progressive muscle relaxation technique between the study group. Meanwhile, such difference was not found between the control group after the application of routine care. This result suggests a possible positive influence of progressive muscle relaxation technique-on reduction of the stress among women after hysterectomy. This results may be attributed to the fact that PMRT can reduce stress symptoms by decreasing activity of stress hormones, rising of blood flow to major muscles, decreasing muscle tension and chronic pain, improving concentration and mood, reducing fatigue, decreasing anger and frustration, enhancing confidence to deal with the problems. ${ }^{[27,28]}$ A similar result was observed in Damodaran et al. $(2015)^{[29]}$ research, they did investigate the stress management among adolescents. They reported that PMRT was effective in terms of reduction in stress and stress manifestations.

The present study results revealed no significant difference in pre intervention anxiety mean scores among the study $(9.525$ $\pm 3.146)$ and control group $(9.525 \pm 3.146)$. However, after intervention, significant difference was noticed among the study and control groups where, a great declined in the anxiety mean scores was obtained by the study group (4.575 \pm 2.011 ) while it was $10.175 \pm 4.679$ for the control group. This finding indicates that progressive PMR are significantly efficient in decreasing anxiety in women after hysterectomy.

This result is in line with Solehati et al. (2014) ${ }^{[30]}$ results. They did a study on the Reduction of Anxiety Level with Benson Relaxation at Cibabat Cimahi Hospital and found that a significant decrease in anxiety state after intervention $(p=.00)$ in post cesarean section. They concluded that the Benson relaxation can decrease anxiety in women with cesarean section. Another study Montazeri-Khadem et al. $(2014)^{[31]}$ had investigated the impact of stress management on volunteer mothers' depression and anxiety to cesarean surgery. They found that mean scores of anxiety compared to the experimental group had a significant reduction.

This result of the present study is in the line with the findings of Özdemir and Pasinlioglu (2009) ${ }^{[32]}$ who found that the mean score of anxiety pre test in study group was $40.9 \pm$ 6.3 , and the post test was $27.6 \pm 3.7$. The difference among the groups was significant $(p=.001)$. Meanwhile, the mean score of anxiety pre test in control group was $41.1 \pm 7.8$, while post test was $40.4 \pm 8.3$ and the difference between the groups was no significant $(p=.625)$. They further elaborated that education and progressive relaxation exercises decrease the level of anxiety in post hysterectomy women. Likewise, and consistently with the present study results, Cheung et al. (2003) ${ }^{[33]}$ who conducted a study on the impact of PMRT on quality of life and anxiety following stoma surgery in patients with colorectal cancer, have found out that the utilization of PMRT significantly improved generic quality of life and reducing anxiety in the study group $(p<.05)$.

These similarities between the present study results and aforementioned results could be attributed to what is elicited in the literature about the affirmative physical and psychological impact of progressive muscle relaxation techniques. Alterations in sympathetic nervous system activity, including reducing in blood pressure, pulse rate, and musculoskeletal tone, as well as altered neuroendocrine function. It has been proposed that profound physical restfulness decrease anxiety and physical arousal. Moreover, PMRT may directly prevent anxiety and the muscular activity which usually precedes nausea and vomiting. ${ }^{[34,35]}$

The current study showed that depression mean score had significantly reduced following the implementation of progressive muscle relaxation technique between the study group. At the same time, such a reduce was not found between the control group after the implementation of routine nursing care. This present study result is supported by Safi S. $(2015)^{[36]}$ and Montazeri-Khadem et al. (2014) ${ }^{[31]}$ studies. The first had studied the Potential Mechanisms of Progressive Muscle Relaxation Therapy on Depression in Female Patients with Multiple Sclerosis. They had concluded that PMRT is efficient in decreasing depression. This therapy enables patients to reach relaxation rapidly, and therefore can handle depression reactions effectively, thus can deal effectively with depression reactions. The second found that mean scores of depression was significantly decreased after the application of progressive muscle relaxation technique among the experimental group than the control one.

The present study result agrees with the results of $\mathrm{Li}$ et al. (2015), ${ }^{[37]}$ Charalambous et al. (2015) ${ }^{[38]}$ and El Malky (2015). ${ }^{[39]}$ The first, had studied Progressive Muscle Relaxation Improves Anxiety and Depression of Pulmonary Arterial Hypertension Patients. They had demonstrated the effectiveness of PMRT as a psychosomatic intervention in Pulmonary Arterial Hypertension patients by reduce anxiety and depression, as well as improve QOL in patients with Pulmonary Arterial Hypertension. The second, had studied the 
Effectiveness of Progressive Muscle Relaxation and Guided Imagery as Anxiety Reducing Interventions in Breast and Prostate Cancer Patients Undergoing Chemotherapy. They found that intervention's mean anxiety and depression score changes were significantly different compared with the Control's. And they concluded that breast and prostate cancer patients who treated with chemotherapy can benefit from Progressive Muscle Relaxation and Guided Imagery sessions to minimize their anxiety and depression. The third, did study about the Effectiveness of Stress Management Programme on Stress, Depression, and Anxiety of Depressed Patients. They had indicated that Progressive Muscle Relaxation technique could have a significant decrease in anxiety, stress, and depression level in the study group compared to the control one. And they concluded that implementation of Progressive Muscle Relaxation technique with depressed patients has a positive impact on decreasing anxiety, stress, and depression.

\section{Conclusion}

Based on the findings of this study, it can be concluded that women who received progressive muscle relaxation technique after hysterectomy demonstrated lower stress, anxiety and depression levels than those who received only the routine nursing care.

Based on the findings of the present study, the following recommendations are suggested:

(1) Maternity and gynecological nurses should integrate progressive muscle relaxation technique as postoperative care into the routine nursing care to increase the efficiency of nursing.
(2) Maternity and gynecological nursing services shoud be used the PMRT as one of the standard operating procedures non pharmacological stress, anxiety and depression management in maternal and gynecological surgical procedure.

(3) The use of PMRT, as a non-pharmacological measure, in maternity hospitals should be ensured.

(4) Maternity and gynecological nurses should be implemented PMRT to women undergoing hysterectomy these techniques as an adjuvant mean to minimize their stress, anxiety and depression.

(5) Relevant nursing curricula must entail a detailed portion about the PMRT for management of post hysterectomy stress, anxiety and depression.

(6) In service training programs for nurses in maternity and gynecological departments-about the utilization of PMRT is recommended.

(7) Future researches

A. Replication of the present study under different circumstances (sampling, setting, measurement, duration of management) is recommended to validate its results.

B. Exploration of the effect of PMRT on management of the different gynecological and reproductive surgery conditions as: Fistula repair, displacement of the pelvic organs and caesarian section.

\section{CONFlicts of InTEREST Disclosure}

The authors declare that there is no conflict of interest.

\section{REFERENCES}

[1] Graesslin O, Martin-Morille C, Leguillier-Amour MC, et al. Local investigation concerning psychic and sexual functioning a short time after Hysterectomy. Gynecol Obstet Fertil. 2002; 30(6): 474-82.

[2] Ewalds SB, Hirvonen T, Kvist M. Depression, Anxiety, Hostilityand Hysterectomy. Journal of Psychosomatic Obstetric Gynecology. 2005; 26(3): 193-204. https://doi.org/10.1080/0144361040 0023163

[3] Donoghe AP, Jackson HJ, Pagano R. Understanding pre- and post Hysterectomy Levels of Negative Affect: A Stress Moderation and Model Approach. Journal of Psychosomatic Obstetric Gynecology. 2003; 4(2): 99-109. https://doi .org/10.3109/016748203090 42807

[4] Vomvolaki E, Kalmantis K, Kioses E, et al. The effect of hysterectomy on sexuality and psychological changes. Eur J Contracept Reprod Health Care. 2006 Mar; 11(1): 23-7. PMid:16546813 https://doi.org/10.1080/13625180500430200

[5] Sharmila R. Preoperative teaching about postoperative care among hysterectomy patients. Nightingale Nursing Times. 2012; 8(6): 6265.

Published by Sciedu Press
[6] Sung MH, Lim YM. Factors Affecting Sexual Satisfaction in Korean Women who Have Undergone a Hysterectomy. Australian Journal of Advanced Nursing. 2010; 27(2): 46-54.

[7] Elweley M, Sabra A. Psychological problems, Concerns and Beliefs in Women Undergoing Hysterectomy. IOSR Journal of Nursing and Health Science. 2015; 4(6): 48-57.

[8] Nilangi S. Hysterectomy among Premenopausal Women and its' impact on their Life-Findings from a study in rural parts of India. International Research Journal of Social Sciences. 2015; 4(4): 15-22.

[9] Shah S, Wagan A, Saud S, et al. Incidence of anxiety and depression in women undergoing hysterectomy. Pakistan Journal of Pharmacology. $2007 ; 24(2): 23-28$.

[10] Khastiger G, Studd J, Catalan J. The Psychological outcome of hysterectomy. Gyneol Endocrinol. 2000; 14(2): 132-41. https: //doi.org/10.3109/09513590009167672

[11] DeCherney A, Bachamann G, Isaacson K, et al. Postoperative fatigue negatively impacts the daily lives of patients recovering from hysterectomy. Obstet Gynecol. 2002; 99(1): 51-7. https: //doi.org/10.1097/00006250-200201000-00011 
[12] Cooper R, Mishra G, Hardy R. Hysterectomy and SubsequentPsychological Health: Findings from a British birth cohort study. Journal of Affect Disorders. 2009; 115(2): 122-30. PMid:18835497 https://doi.org/10.1016/j.jad.2008.08.017

[13] Sehlo MG, Ramadani H. Depression Following Hysterectomy. Journal of Current Psychiatry. 2010; 17(2): 1-5.

[14] Karen Lee F. Complementary and Alternative Therapies for Nursing Practices. 2nd. New Jersey: Pearson Education. 2000; 143-53.

[15] Elaines Z, Johnson K. How to Implement Complementary Therapies for laboring women. American Journal of Maternity, Child Nursing. 2006; 31(6): 364-70.

[16] Townsend MC. Psychiatric mental health nursing concept of care 5th edition. Philadelphia: F. A Davis publishers; 2005.

[17] Conrad A, Roth WT. Muscle relaxation therapy for anxiety disorders: It works but how? Journal of Anxiety Disorders. 2007; 21: 243-264. PMid:16949248 https ://doi.org/10.1016/j.janxdis. 2006 .08 .001

[18] Payne R, Donaghy M. Payne's Handbook of Relaxation Techniques: a practical guide for the health care professional. Fourth Edition. London: Churchill Livingstone, Elsevier; 2010.

[19] Jeong I. effect of progressive muscle relaxation using biofeedback on perceived stress, stress response, immune response and climacteric symptoms of middle-aged women. Journal of Medicine. 2004; 34(2): 113-30.

[20] Krupińska K, Kulmatycki L. Effectiveness of Progressive Muscle Relaxation(Pmr) In Alleviating Psychophysical Disorders-A Systematic Review(1982-2012). GJRA- Global Journal for Research Analysis. 2014; 3(10): 113-115.

[21] Jacobson E. Progressive Relaxation. University of Chicago Press, Chicago (2nd Ed.) 1938; 64-68.

[22] Cooke H. Progressive Muscle Relaxation. CAM-Cancer J. 2013; 1(1): $1-6$.

[23] Lovibond P. Long-term stability of depression, anxiety, and stress syndromes. J Abnormal Psychol. 1998; 107(3): 520-6. https: //doi.org/10.1037/0021-843X.107.3.520

[24] Antony M, Bieling P, Cox B, et al. Psychometric properties of the 42item and 21-item versions of the Depression anxiety stress scales in clinical groups and a community sample. Psychological Assessment. 1998; 10: 176-181. https://doi.org/10.1037/1040-3590.10 .2 .176

[25] Sharma A, Zhan J. Depression and its predictors among breast cancer patients in Nepal. ASEAN Journal of Psychiatry. 2015; 16(1): 1-10.

[26] Saevarsdottir T, Fridriksdottir N, Gunnarsdottir S. Quality of life and symptoms of anxiety and depression of patients receiving cancer chemotherapy: longitudinal study. Cancer Nursing. 2010; 33(1): E1-E10. PMid:20010331 https://doi.org/10.1097/NCC.0b $013 e 3181 \mathrm{~b} 4 \mathrm{adb5}$

[27] Hui N, Wan M, Chan K, et al. An evaluation of two behavioral rehabilitation programs, qigong versus progressive relaxation, in im- proving the quality of life in cardiac patients. J Altern Complement Med. 2006; 12(4): 373-8. PMid:16722787 https ://doi .org/10 $.1089 / \mathrm{acm} .2006 .12 .373$

[28] Freeman L. Meditation: Complementary and Alternative Medicine: A Research-Based Approach, 3rd ed. St. Louis: Mosby Elsevier; 2009; 129-188.

[29] Damodaran D, Paul V. Stress Management among Adolescents. The International Journal of Indian Psychology. 2015; 3(1): 104-111.

[30] Solehati T, Rustina Y. The Reduction of Anxiety Level with Benson Relaxation at Cibabat Cimahi Hospital. Journal of Nursing and Health Care (JNHC). 2014; 1(2): 167-171. https ://doi .org/10 $.5176 / 2345-718 x_{-} 1.2 .52$

[31] Montazeri-Khadem V, Mohammadi R, Haghayegh S, et al. The effectiveness of stress management on volunteer mothers' anxiety and depression to cesarean surgery. International Journal of Psychology and Behavioral Research. 2014; 1(4): 567-571.

[32] Özdemir F, Pasinlioglu T. The Effects of Training and Progressive Relaxation Exercises On Anxiety Level After Hysterectomy. The New Journal of Medicine. 2009; 26: 102-107.

[33] Cheung L, Molassiotis A, Chang M, et al. The effect of progressive muscle relaxation training on anxiety and quality of life after stoma surgery in colorectal cancer patients. Psycho-Oncology. 2003; 12(3): 254-66. Hong Kong. PMid:12673809 https : //doi .org/10. 100 $2 /$ pon. 638

[34] Payne R, Donaghy M. Payne's Handbook of Relaxation Techniques: a practical guide for the health care professional. 4th ed. London: Churchill Livingstone, Elsevier; 2010.

[35] Yilmaz S, Arslan S, Arslan S. Effects of Progressive Relaxation Exercises on Anxiety and Comfort of Turkish Breast Cancer Patients Receiving Chemotherapy. Asian Pacific Journal of Cancer Prevention. 2015; 16(1): 217-220. PMid:25640354 https://doi.org/10.7 314/AP JCP. 2015.16.1.217

[36] Safi S. A Fresh Look at the Potential Mechanisms of Progressive Muscle Relaxation Therapy on Depression in Female Patients with Multiple Sclerosis. Iran J Psychiatry Behav Sci. 2015; 9(1): 1-7. PMid:26251663 https ://doi.org/10.17795/ijpbs340

[37] Li Y, Wang R, Tang J, et al. Progressive Muscle Relaxation Improves Anxiety and Depression of Pulmonary Arterial Hypertension Patients. Evidence-Based Complementary and Alternative Medicine. 2015; 1-8. PMid:26246836 https ://doi .org/10.1155/2015/468520

[38] Charalambous A, Giannakopoulou M, Bozas E, et al. A Randomized Controlled Trial for the Effectiveness of Progressive Muscle Relaxation and Guided Imagery as Anxiety Reducing Interventions in Breast and Prostate Cancer Patients Undergoing Chemotherapy. Evidence-Based Complementary and Alternative Medicine. 2015; 110. PMid:26347018 https : //doi .org/10.1155/2015/270876

[39] El Malky M, Atia M, El-Amrosy S. The Effectiveness of Stress Management Programme on Depression, Stress, and Anxiety of Depressed Patients. Journal of Nursing Science. 2015; 1(2): 15-24. 